\title{
ACESSO AO PODER JUDICIÁRIO NA ERA DIGITAL: UMA ABORDAGEM SOBRE O IMPACTO DA TECNOLOGIA PARA PESSOAS QUE VIVEM NA POBREZA
}

\author{
Natan Figueredo Oliveira*
}

\section{RESUMO}

Este artigo tem o propósito de analisar o impacto que as inovações tecnológicas nos serviços judiciários têm para o acesso à justiça das pessoas que vivem na pobreza. Traça uma definição de pobreza com base nas abordagens das "necessidades básicas" e "capacidades". Investiga, por meio de pesquisa descritiva, qualitativa, de cunho bibliográfico, a relação da falta de acesso à internet e a equipamentos eletrônicos com o acesso ao Poder Judiciário. Pondera-se, ao fim, como as medidas de inclusão digital podem otimizar os serviços e alcançar as pessoas em situação de pobreza e, assim, democratizar o acesso à justiça.

PALAVRAS-CHAVE: Poder Judiciário; Acesso à justiça; Pobreza; Tecnologia; Inclusão digital

\section{ACCESS TO COURTS IN THE DIGITAL AGE: AN APPROACH ON THE IMPACT OF TECHNOLOGY FOR PERSONS LIVING IN POVERTY}

\begin{abstract}
This article analyze the impact that technological innovations in judicial services have on access to justice for people living in poverty. It draws a definition of poverty based on "basic needs" and "capacities" approaches. It investigates, through descriptive, qualitative, bibliographical research, the relationship between lack of access to the internet and electronic equipment and access to the courts. Finally, it is considered how digital inclusion measures can optimize services and reach people in poverty and, thus, democratize access to justice.
\end{abstract}

KEYWORDS: Judiciary; Access to justice; Poverty; Technology; Digital inclusion

\section{INTRODUÇÃO}

A ideia de acesso à justiça não está limitada ao acesso formal ao Poder Judiciário, compreendendo múltiplas perspectivas que contemplam o acesso a uma ordem de valores e direitos fundamentais. Porém, garantir o acesso à justiça, por meio do Poder Judiciário, com oportunidades reais de atendimento e em igualdade de condições ainda constitui uma demanda social.

O monopólio estatal da jurisdição convive com medidas de desjudicialização de conflitos 1 e de tratamento dos litígios por meios autocompositivos e heterocompositivos

\footnotetext{
* Mestrando em Processo e Direito ao Desenvolvimento pelo Centro Universitário Christus. Especialista em Direito Público. Especialista em Direito Público pela ESMAPE. Juiz de Direito no Estado da Paraíba. E-mail: onatanfigueredo@gmail.com.
} 
extrajudiciais e, apesar de tais medidas, o Poder Judiciário continua com elevado número de processos e com repercussão direta na eficiência do serviço. Há, porém, "uma situação paradoxal: a simultaneidade da existência de demandas demais e demandas de menos; ou, dizendo-o de outra forma, poucos procurando muito e muitos procurando pouco" (SADEK; LIMA; ARAÚJO, 2001, p. 40).

Trata-se de uma realidade mundial, tendo em vista que 3,8 bilhões de pessoas que vivem na pobreza encontram-se impedidas de reivindicar os seus direitos mais básicos através de um sistema de justiça, por razões de exclusão social e política2.

A relação entre acesso à justiça e pobreza envolve uma série de aspectos referentes a cada uma dessas variáveis, resultando numa multiplicidade de problemas a serem enfrentados. Ocorre que, no atual estágio da sociedade, em que o uso da tecnologia não é apenas uma realidade, mas uma necessidade em quase todos os campos da vida, convém examinar o acesso à justiça na era das inovações tecnológicas e da justiça digital. Em outras palavras, é relevante abordar o impacto da tecnologia para as pessoas que vivem na pobreza no momento em que os serviços passam a ser prestados pelos órgãos judiciários por meios digitais.

$\mathrm{Na}$ primeira parte deste artigo é desenvolvido um conceito de pobreza a partir das abordagens das "necessidades básicas" e das "capacidades", demonstrando como a pobreza está relacionada com a privação de outras variáveis como doença, baixo nível de instrução, falta de conhecimento de direitos, além da medida de renda. Assim, identifica-se quem é o pobre que não acessa a justiça e investiga-se, de forma breve, como a pobreza tem sido tratada na lei.

$\mathrm{Na}$ sequência, trata-se do acesso à justiça através do Poder Judiciário, numa perspectiva de reivindicação formal de direitos ou de possibilidade de provocar o Poder Judiciário, por meio de um procedimento previsto em lei, com as garantias constitucionais de duração razoável, contraditório e um resultado justo, mediado pela tecnologia e com foco nas dificuldades enfrentadas pelas pessoas cujo acesso às tecnologias digitais, em especial à internet, é muito restrito ou inexistente.

Por fim, apresenta-se uma visão otimista de como a assistência digital pode ser um caminho para assegurar o acesso universal ao Poder Judiciário na era digital.

1 A título de exemplo, podem ser citados o reconhecimento de paternidade perante os serviços de registro civil, recuperação de empresa extrajudicial, usucapião extrajudicial, divórcio consensual extrajudicial.

2 De acordo com o Projeto Global Acess to Justice. Disponível em: https://globalaccesstojustice.com. Acesso em 10 ago. 2021. 
$\mathrm{Na}$ pesquisa foram utilizados os métodos descritivo, qualitativo, bibliográfico (especialmente por livros, artigos científicos e legislação) e dedutivo, que se revelam compatíveis com os objetivos propostos.

\section{A IDENTIFICAÇÃO DAS PESSOAS QUE VIVEM NA POBREZA: QUEM SÃO OS POBRES?}

A pobreza não é um estado ou situação de fácil definição, podendo ser encarada por dimensões e parâmetros diversos. Mas, mesmo em concepções distintas, é possível identificar termos coincidentes ou empregados com frequência como "privação", "bem-estar", "renda", "capacidade", "desenvolvimento humano" . Assim, observa-se que as abordagens direcionamse ou a qualidades monetárias, tendo por consequência considerar que a redução da pobreza está mais associada a impulso e crescimento econômico, ou a qualidades humanísticas, vinculando-a a uma proposta de superação por meio do desenvolvimento humano (WONG, 2012).

Legalmente, percebe-se que a condição de pessoa pobre no Brasil tem sido aferida, via de regra, pelo seu nível de renda. Para fins de assistência judiciária gratuita, por exemplo, é tradicional a orientação de se considerar a insuficiência de recursos financeiros da pessoa, como se verifica da Constituição de $1934^{4}$, da Constituição de $1946^{5}$, da Constituição de $1967^{6}$ e respectivo dispositivo na Emenda n $1 / 1969^{7 .}$

A Lei $n^{\circ}$ 1.060/1950 empregou como expressões sinônimas "assistência judiciária" e "justiça gratuita", indicando como beneficiário o necessitado, assim reputado "todo aquele cuja situação econômica não lhe permita pagar as custas do processo e os honorários de

\footnotetext{
3 O Índice de Desenvolvimento Humano - IDH, desenvolvido a partir das ideias do economista Amartya Sen e empregado pelo Programa das Nações Unidas para o Desenvolvimento - PNUD, consiste numa medida que agrega dimensões como saúde, educação e padrão econômico de vida (PIB e renda per capita) para promover comparação de desenvolvimento dos países.

4 113, 32. A União e os Estados concederão aos necessitados assistência judiciária, criando para esse efeito, órgãos especiais, assegurando, a isenção de emolumentos, custas, taxas e selos.

5 Art. 141, §35 - O Poder Público, na forma que a lei estabelecer, concederá assistência judiciária aos necessitados.

6 Art. 250, § 32 - Será concedida assistência judiciária gratuita aos necessitados, na forma da lei.

7 Art. $153, \S 2^{\circ}-$ Será concedida assistência judiciária gratuita aos necessitados, na forma da lei
} 
advogado, sem prejuízo do sustento próprio ou da família”, conforme artigo $2^{\circ}$, parágrafo único. No mesmo sentido, o Código de Processo Civil tratou do tema .

Ainda com base no nível de renda e especificando o parâmetro de renda mínima, a Lei n ${ }^{\text {o }} 10.836 / 2004^{9}$, que criou o Bolsa Família10, programa de transferência de renda do Governo Federal, destinando um benefício financeiro, mediante condições, a unidades familiares em situação de pobreza e extrema pobreza, adotou o valor de renda mensal familiar para configurar a pobreza ou extrema pobreza, e o Decreto $n^{\circ} 9.396 / 2018$ estabeleceu qual o parâmetro de renda para cada uma das situações.

Em paralelo, a Lei $n^{\circ}$ 8.472/1993, que dispõe sobre a organização da assistência social, prevê a possibilidade de pagamento de benefício mensal para pessoa em situação de vulnerabilidade social, assim considerada a pessoa com deficiência e o idoso com 65 anos, ou mais, cuja renda familiar mensal per capita seja igual ou inferior a 1/4 do salário-mínimo. Nesse caso, o benefício concedido a um idoso não será computado na renda familiar para aferir a possibilidade de concessão de outro benefício de igual natureza a outro idoso ou pessoa com deficiência da mesma família ${ }^{12}$.

Sem pretender esgotar a matéria, os exemplos trazidos demonstram como a condição de pobreza tem sido tratada na legislação, revelando que as definições legais estão essencialmente vinculadas a uma renda inadequada para o sustento. Tais definições não se mostram satisfatórias para os fins de compreender a pobreza real. Isso significa que mesmo

\footnotetext{
8 Art. 98. A pessoa natural ou jurídica, brasileira ou estrangeira, com insuficiência de recursos para pagar as custas, as despesas processuais e os honorários advocatícios tem direito à gratuidade da justiça, na forma da lei. 9 Art. $2^{\circ}[\ldots] \S 1^{\circ}$ Para fins do disposto nesta Lei, considera-se: [...] "III - renda familiar mensal, a soma dos rendimentos brutos auferidos mensalmente pela totalidade dos membros da família, excluindo-se os rendimentos concedidos por programas oficiais de transferência de renda, nos termos do regulamento".

10 Alterado recentemente pela Medida Provisória n ${ }^{\circ}$ 1.061, de 09 de agosto de 2021, que instituiu o Programa Auxílio Brasil e o Programa Alimenta Brasil.

11 Art. 18. O Programa Bolsa Família atenderá às famílias em situação de pobreza e de extrema pobreza, caracterizadas pela renda familiar mensal per capita de até $\mathrm{R} \$ 178,00$ (cento e setenta e oito reais) e $R \$ 89,00$ (oitenta e nove reais), respectivamente.

12 Art. 20. O benefício de prestação continuada é a garantia de um salário-mínimo mensal à pessoa com deficiência e ao idoso com 65 (sessenta e cinco) anos ou mais que comprovem não possuir meios de prover a própria manutenção nem de tê-la provida por sua família. [...] $\S 3^{\circ}$ Observados os demais critérios de elegibilidade definidos nesta Lei, terão direito ao benefício financeiro de que trata o caput deste artigo a pessoa com deficiência ou a pessoa idosa com renda familiar mensal per capita igual ou inferior a $1 / 4$ (um quarto) do salário-mínimo; [...] § 14. O benefício de prestação continuada ou o benefício previdenciário no valor de até 1 (um) salário-mínimo concedido a idoso acima de 65 (sessenta e cinco) anos de idade ou pessoa com deficiência não será computado, para fins de concessão do benefício de prestação continuada a outro idoso ou pessoa com deficiência da mesma família, no cálculo da renda a que se refere o $\S 3^{\circ}$ deste artigo.
} 
que a insuficiência de renda seja uma predisposição para uma vida pobre, outras capacidades devem ser apreciadas na consideração dessa vida pobre.

Para este artigo a apresentação das abordagens das "necessidades básicas" e das “capacidades" serão o ponto de inflexão.

De modo simplificado, diz-se que, para abordagem das "necessidades básicas", os pobres são as pessoas privadas de um pacote de bens de consumo básicos, universalmente necessários, como alimento, abrigo, saneamento, água potável, cujo elenco é passível de reavaliação em nível local e de acordo com o tempo, possibilitando a subsistência e uma vida decente (WONG, 2012).

A crítica apresentada a essa abordagem considera que a imposição de um pacote de necessidades básicas comuns compreende uma postura paternalista, porque as escolhas dos bens essenciais é feita por um terceiro e de forma generalizada, desprezando que a hierarquia entre as necessidades possui peculiaridades pessoais com respectiva ordem de prioridades. Logo, não seria adequada a adoção de um pacote pronto de necessidades básicas universais, pois, por exemplo, a sobrevivência pode ser comprometida por falta de comida, mas não na mesma medida pela falta de abrigo. Ademais, o enfoque na privação monetária e, por consequência, em aspectos materiais, não compreenderia que a pobreza pode estar atrelada a valores e aspirações (WONG, 2012).

A segunda abordagem - a das "capacidades" - argumenta que a pobreza compreende não apenas aquilo que as pessoas estão privadas de ter, mas também a insuficiência de valorização de algo que se possa fazer e ser, incluindo nesse contexto questões como participação social, possibilidade de espalhar ideias, ser respeitado etc. Em outros termos, sem ênfase excessiva nos aspectos econômicos e levando em conta a deliberação das pessoas sobre o que para elas é essencial, a pobreza também se configura pelas insuficiências sociais e pessoais.

O enfoque da pobreza como privação de capacidades tem como expoente Amartya Sen13, para quem o pobre não é apenas aquele privado de bens materiais, mas quem também sofre privações em outras esferas de sua vida e que determinam o seu posicionamento como

13 Amartya Sen é economista indiano e ganhador do prêmio Nobel de Economia em 1999. Esclareça-se que o prêmio criado por Alfred Nobel e entregue desde 1901 contemplou, originalmente, as seguintes categorias: Física, Literatura, Medicina, Paz e Química. O prêmio Nobel de Economia, entregue a partir de 1969 se trata do Prêmio do Banco da Suécia para Ciências Econômicas em Memória de Alfred Nobel. 
cidadão (CRESPO; GUROVITZ, 2002). Em outras palavras, Sen não exclui os padrões monetários, adiciona outros critérios que se combinam com a renda e nela influenciam.

\begin{abstract}
Nessa perspectiva, a pobreza deve ser vista como privação de capacidades básicas em vez de meramente como baixo nível de renda, que é o critério tradicional de identificação da pobreza. A perspectiva da pobreza como privação de capacidades não envolve nenhuma negação da ideia sensata de que a renda baixa é claramente uma das causas principais da pobreza, pois a falta de renda pode ser uma razão primordial da privação de capacidades de uma pessoa. Uma renda inadequada é, com efeito, uma forte condição predisponente de uma vida pobre. Já que isso é aceito, então porque tanta preocupação em ver a pobreza da perspectiva da capacidade (em vez da clássica avaliação da pobreza com base na renda)? (SEN, 2010, p. 120).
\end{abstract}

Com efeito, a pobreza pode ser acentuada a partir de outros fatores, em conjugação com a renda, como idade da pessoa (por exemplo, crianças e idosos), papéis sexuais e sociais (por exemplo, maternidade e costumes), localização (por exemplo, regiões geográficas propensas a secas ou inundações, ou mais populosas ou mais violentas, zona rural e zona urbana), condições epidemiológicas e outras variações incontroláveis ou de controle limitado (SEN, 2010, p. 121). Ademais,

[...] pode haver um certo "acoplamento" de desvantagens entre (1) privação de renda e (2) adversidade na conversão da renda em funcionamentos. Desvantagens como a idade, incapacidade ou doença reduzem o potencial do indivíduo para auferir renda. Mas também tornam mais difícil converter renda em capacidade, já que uma pessoa mais velha, mais incapacitada, ou mais gravemente enferma pode necessitar de mais renda (para assistência, prótese, tratamento) para obter os mesmos funcionamentos (mesmo quando essa realização é de algum modo possível). Isso implica que a "pobreza real" (no que se refere à privação de capacidades) pode ser, em um sentido significativo, mais intensa do que pode parecer no espaço da renda (SEN, 2010, p. 121).

Com efeito, a noção de pobreza por inadequação de capacidade está vinculada a noção de pobreza em decorrência de baixa renda, mas, como dito, tal vinculação não é isolada e se relaciona com as liberdades da pessoa.

Para operacionalizar o conceito de pobreza que atenda aos fins deste estudo nenhuma das abordagens ("capacidades" e "necessidades básicas") deve ser desprezada. Assim, em vez de antagonismo, prefere-se buscar a integração das duas abordagens, que, combinadas, melhor explicam as dificuldades de acesso à justiça pelas pessoas que vivem na pobreza.

Em suma, a superação da pobreza depende da ampliação de possibilidades de escolhas distintas para diferentes pessoas e com oportunidades de levar uma vida longa, saudável e criativa e gozar de um padrão de vida decente, com liberdade, dignidade, respeito próprio e respeito pelos outros (WONG, 2012). Isso requer mais do que insumos materiais, demandando insumos institucionais, sociais ou culturais em diversos níveis. 
Nesse cenário, torna-se relevante tratar das dificuldades das pessoas em situação de pobreza terem acesso à justiça, pois tal dificuldade pode decorrer da privação de capacidades e da falta de acesso a um pacote básico de insumos para sobrevivência e, simultaneamente, como faces de uma mesma moeda, a dificuldade de acesso à justiça pode aumentar tais privações (de capacidades e necessidades).

Por isso, propõe-se considerar que a ordem constitucional, ao salvaguardar a tutela dos direitos e garantir a assistência para os insuficientes de recursos, não impõe que a insuficiência seja apenas de recursos financeiros. Nesse sentido, a previsão do artigo $5^{\circ}$, LXXIV, da Constituição Federal , não adjetiva o substantivo "recursos".

Apropriando-se dessa abordagem sobre a pobreza, é que se poderá estabelecer condições de oportunidade real e universal de acesso à justiça e, nesse sentido, mostra-se oportuno analisar o impacto da tecnologia na acessibilidade ao Poder Judiciário.

\section{O ACESSO À JUSTIÇA POR MEIO DO PODER JUDICIÁRIO}

A polissemia do termo justiça se reflete na noção difusa de acesso à justiça. "A expressão 'acesso à justiça' é reconhecidamente de difícil definição" (CAPPELLETTI; GARTH, 1988, p. 8), podendo representar um pressuposto para legitimidade das instituições públicas, um serviço público, um direito fundamental ou um elemento integrante de um ou de vários direitos fundamentais, como o devido processo legal, um meio de sanar injustiças em sentido amplo (MORENO, 2020, p. 155).

Por muito tempo a expressão "acesso à justiça" foi considerada sinônimo de "acesso ao Poder Judiciário", mas, hoje parece ser consenso que a primeira expressão constitui gênero do qual a segunda é espécie. Assim, acesso à justiça corresponde ao acesso a uma ordem de valores e direitos fundamentais que incluem, por exemplo, o direito de acesso aos órgãos jurisdicionais, a uma ordem jurídica justa (WATANABE, 1988, p. 128), à educação em direitos e à "mais ampla tutela dos direitos do cidadão" (SPENGLER; PINHO, 2018, p. 225).

Sob diferentes espécies de acesso à justiça são estabelecidas diferentes políticas para garanti-lo.

Historicamente, as políticas públicas relacionadas ao acesso à justiça na América latina podem ser divididas em três fases, contemplando, em resumo, o movimento de direito e

14 Art. $5^{\circ}$, LXXIV - O Estado prestará assistência jurídica integral e gratuita aos que comprovarem insuficiência de recursos. 
desenvolvimento que mudou o método de ensino do direito, incentivando a prestação de assessoria jurídica aos pobres, pelos estudantes; as políticas de desjudicialização de certos assuntos; a promoção de um direcionamento das políticas públicas para a assistência jurídica às pessoas com escassos recursos econômicos ou minorias sociais, mediante a criação de sistemas paralelos ao institucional, nos quais os cidadãos têm papel mais ativo na solução dos seus conflitos. Esta última etapa é conhecida como do acesso à justiça propriamente dito e na qual está também inserido o enfoque de enfrentamento das barreiras de acesso à justiça pela população vulnerável (CUERVO apud MORENO, 2020, p. 156-157).

Sobre o tema destaca-se, ainda, o difundido estudo de direito comparado feito por Mauro Cappelletti e Bryant Garth (1988) no livro Acesso à justiça, que comparou, por meio de levantamento histórico em vários países, os obstáculos a serem removidos para o acesso à justiça, apresentando as soluções práticas propostas, tratadas num recorte com diferentes características, chamadas de três ondas renovatórias. A primeira onda coincide com a prestação de assistência jurídica aos pobres. A segunda onda com a representação dos interesses difusos e a terceira com o aprimoramento dos procedimentos e instituições que processam os litígios.

Além dessa tripartição clássica, atualmente já se fala em novas ondas de remoção das barreiras de acesso à justiça, relacionadas à internacionalização de processos que tratam de direitos humanos e também com relação ao impacto das novas tecnologias na sociedade 15.

Quanto a esta última onda ou barreira, atinente a novas tecnologias, convém indagar em que medida isso tem afetado o acesso ao Poder Judiciário.

Ora, muitas razões podem ser invocadas como justificativa para que grande parte da população não acesse o Poder Judiciário. Primeiro, há necessidades jurídicas que podem ser supridas com sucesso sem socorro ao Poder Judiciário, através de outras instâncias de poder ou canais alternativos como a mediação extrajudicial, por exemplo. Outrossim, há situações que, sem dúvidas, podem ser e são resolvidas pelos próprios interessados, como questões nas quais vizinhos acordam sobre a poda de uma árvore sem discutir os limites de suas propriedades, ou casos em que locador e locatário promovem arranjos informais para flexibilizar a data do pagamento do aluguel atrasado.

15 Nesse sentido, confira-se o Global Acess to Justice, que é um projeto que "procura identificar, mapear e analisar essas tendências emergentes, realizando uma nova pesquisa global (...) adotando uma abordagem teórica e geográfica abrangente no mapeamento e estudo do diversificado movimento mundial de acesso à justiça na África, Ásia, Oriente Médio, América Latina, América do Norte, Europa e Oceania”. Disponível em: https://globalaccesstojustice.com/. Acesso em: 10 jul. 2021. 
Entretanto, há situações que dependem efetivamente da intervenção do Estado-juiz, diante da lesão ou ameaça de lesão a direito, como nos casos de investigação de paternidade, execução de alimentos, reintegração de posse 16 e, nessas hipóteses, especificamente para a camada da população que vive na pobreza, podem subsistir antigas barreiras para acessar o Poder Judiciário como instância de garantia do devido processo constitucional (justo, equitativo, com efetivo contraditório), em consonância com o artigo $5^{\circ}, \mathrm{XXXV}$ da Constituição Federal17.

Pode-se elencar como motivos para isso a falta de acesso à representação jurídica (falta de condições financeiras de contratar advogados ou falta de proximidade da Defensoria Pública), desconhecimento sobre seus direitos 18 (que leva as pessoas a considerar a falta de gozo de direito ou de satisfação de uma necessidade específica como "má sorte", "parte da vida", "parte dos planos de Deus") (SANDEFUR, 2016), distância geográfica da residência para os locais onde estão instalados os serviços judiciários (que impõe que algumas pessoas gastem mais tempo, esforço e planejamento para se deslocar aos locais físicos em busca de seus direitos, condicionando oportunidades e perspectivas de vida) (YOUNG, 2001).

É possível cogitar, também, que as pessoas deixem de buscar o Poder Judiciário por sentimentos de constrangimento ou vergonha de publicizar o seu problema ou em razão de experiências anteriores que gerem medo, resignação, sensação de impotência, relacionados com a crença de que não podem prevalecer ao confrontar a outra parte, ou por não ter conseguido resolver, pela via judicial, problema semelhante anteriormente, e, ainda, pela demora na reposta a questões apresentadas ao Poder Judiciário (SANDEFUR, 2007).

Todas essas vertentes agora estão associadas em alguma medida à incorporação da tecnologia na sociedade e no Poder Judiciário. Nesse passo, tem-se presenciado um crescente movimento do Poder Judiciário de internalização de tecnologias que ampliem o acesso à justiça e melhorem a prestação jurisdicional, notadamente considerando o elevado acervo de

16 Esses são apenas alguns exemplos no campo do direito civil e que podem ser ampliados significativamente para outras áreas do direito.

17 Art. 5º XXXV - A lei não excluirá da apreciação do Poder Judiciário lesão ou ameaça a direito.

18 A educação em direitos é alternativa potencialmente mais adequada para afastar a barreira da informação, cultura e, ao cabo, da pobreza real. Trata-se de um aspecto da cidadania, que não se confunde com ensino cívico, nem com ensino formal, mas de uma possibilidade de conscientização ampla de cidadania, de direitos humanos, de informação sobre deveres imediatos (alimentos, capacidade eleitoral, fiscalização de contas públicas, saúde, autotutela etc), mas que também contemple o tratamento das relações de poder, das estruturas sociais, de temas sensíveis às minorias como questões de raça e gênero, trabalhando a noção de dignidade humana. Desde o advento da Lei Complementar no 132/2009, que alterou a Lei Complementar $n^{\circ}$ 80/1994 (arts. $4^{\circ}$, III e 134), a educação em direitos passou a ser função institucional da Defensoria Pública, instituição vocacionada, por previsão constitucional, à orientação dos necessitados. 
processos em tramitação no Brasil19. Em 2006, o processo eletrônico foi instituído, com base na Lei $n^{\circ}$ 11.419/2006, e desde 2013, a Resolução ${ }^{\circ} 185$ do Conselho Nacional de Justiça tornou obrigatório o processo eletrônico para todos os tribunais. E, ainda, com o advento da pandemia da COVID-19, os serviços judiciários por meios eletrônicos foram ampliados 20.

\section{O IMPACTO DA TECNOLOGIA COMO MEDIADORA DO ACESSO À JUSTIÇA POR MEIO DO PODER JUDICIÁRIO}

Está em curso a quarta revolução industrial21, com ondas inovatórias que fundem domínios físicos, digitais e biológicos, caracterizada, especialmente, pela internet ubíqua e móvel e pela inteligência artificial. A maior novidade não está na existência de tecnologia digital, baseada em computadores, softwares e redes, mas na integração dela na sociedade (SCHWAB, 2016). É uma verdadeira era digital que alcança as mais diversas manifestações humanas, tais como a forma de se comunicar, de negociar, de estudar, de trabalhar, e, igualmente, de reconhecer, distribuir e reivindicar direitos.

Aqui utiliza-se a expressão "era digital" por considerar o tempo de transformação, por meios digitais, da economia, da política, da cultura, da comunicação, da medicina e outras áreas.

O termo "digitalização" refere-se inicialmente apenas às tecnologias da informação
específicas que processam dados digitais e às infraestruturas (software e hardware)
criadas para as tecnologias digitais. No entanto, o termo também representa a
mudança fundamental nas condições de vida desencadeada pela sua utilização em
todo o mundo. Permite a utilização de sistemas ciberfísicos para novos processos de
produção em rede e automatizados (por exemplo, na indústria 4.0), alterações na
forma como as pessoas vivem as suas vidas (por exemplo, na "casa inteligente"), a
criação e utilização de redes sociais (como o Google ou o Facebook) e outros novos
serviços de comunicação (por exemplo, mensagens instantâneas), bem como novos
sistemas de vigilância por empresas privadas e agências governamentais
(HOFFMANN-RIEM, 2021,E-book).

Por isso, não se estranha que esse movimento irrefreável de imersão na tecnologia também alcance as relações jurídicas, diante da sempre presente busca por ganho de eficiência e produtividade nas atividades jurídicas.

Nas três últimas décadas, temos vivido no Brasil o fenômeno da hiperjudicialização, que se traduz no exponencial crescimento do número de processos judiciais. A

19 Segundo a última pesquisa Justiça em Números, 77,1 milhões de processos tramitavam no Brasil no final de 2019 (BRASIL, 2020).

20 A título de exemplo, o Conselho Nacional de Justiça editou as Resoluções n ${ }^{\circ}$ 62/2020, $n^{\circ} 313 / 2020$ e $n^{\circ}$ 217/2020, regulamentando a prática de audiências por videoconferência, atos processuais eletrônicos e perícias virtuais.

21 Outras expressões são utilizadas para este contexto, como pós-modernidade, sociedade da informação, sociedade pós-industrial, etc para designar essa mudança na sociedade promovida especialmente pela tecnologia. 
despeito de várias reformas processuais e dos esforços para promover métodos consensuais e extrajudiciais de resolução de conflitos, as estatísticas indicam que o país tem um dos maiores estoques de processos do mundo, com aproximadamente 80 milhões de processos, e um elevado índice de congestionamento, cerca de $70 \%$ apesar de contarmos com cerca de 18 mil juízes, cuja produtividade tem aumentado ao longo do tempo. Esse fenômeno, além de dificultar o acesso à justiça e ampliar desarrazoadamente a duração dos processos, tem também elevado significativamente o custo de manutenção do sistema de justiça, que, segundo dados do CNJ, corresponde a cerca de $1,4 \%$ do PIB, muito maior do que se despende em países desenvolvidos. Paralelamente, o atual estágio da sociedade da informação demanda a modernização do Estado, não apenas para fazer frente a esse número expressivo de demandas, como também para possibilitar a mineração de dados estratégicos para o planejamento da gestão. Nesse contexto, o uso da tecnologia não é apenas uma realidade, mas uma necessidade. (CUEVA, 2021).

A propósito, isso já é uma realidade no Poder Judiciário, cujas políticas pretendem assegurar o amplo acesso à justiça com aposta na tecnologia, conforme programas implementados pelo Conselho Nacional de Justiça que incentivam soluções de automação e uso de inteligência artificial pelos tribunais e outras práticas22. Além disso, é corrente que os processos já tramitam em plataforma eletrônica (o conhecido Processo Judicial Eletrônico PJe) e que as audiências têm sido realizadas por videoconferência23.

Destacam-se alguns ganhos presumivelmente decorrentes da mediação do acesso à justiça pela tecnologia: a) redução do custo no fornecimento dos serviços e de mão de obra, de modo a permitir que a economia auferida seja destinada à prestação de serviços adicionais que aproximem o cidadão dos órgãos judiciais; b) automação de procedimentos e aceleração de atos processuais, resultando em diminuição do tempo de tramitação dos processos; c) o atendimento on-line ou virtual possibilita uma maior capilaridade para o sistema de justiça desenvolver funções (a busca de registro civil, apresentação de notícia-crime, promoção de conciliações, o tradicional processamento de demandas e outras atividades); d) remoção das barreiras geográficas (SALDANHA; MEDEIROS, 2018, p. 5), permitindo que as pessoas

22 O Conselho Nacional de Justiça (CNJ) tem incentivado o uso de tecnologias nos tribunais de todo o país como meio de otimizar a prestação jurisdicional por meio da ciência de dados e da inteligência artificial. O CNJ desenvolve o "Programa Justiça 4.0" em parceria com o Programa das Nações Unidas para o Desenvolvimento (PNUD) e o Conselho da Justiça Federal (CJF), contemplando um "um conjunto de projetos e ações, como a Plataforma Digital do Poder Judiciário, o Juízo 100\% Digital, o Balcão Virtual e o Núcleo Justiça 4.0". Nesse contexto, foi editada a Resolução ${ }^{\circ} 332$, de 21/08/2020, que dispõe sobre a ética, a transparência e a governança na produção e no uso de Inteligência Artificial no Poder Judiciário e dá outras providências, bem como as Resoluções $n^{\circ} 345$, de 09/10/2021, $n^{\circ} 372$, de 12/02/2021 e $n^{\circ} 385$, de 06/04/2021, que tratam das medidas previstas no "Programa Justiça 4.0". Disponíveis em: https://atos.cnj.jus.br/atos/detalhar/3429, https://atos.cnj.jus.br/atos/detalhar/3512, https://atos.cnj.jus.br/atos/detalhar/3843. Acesso em 10 jun. 2021.

23 Mesmo antes da pandemia de COVID-19 que impôs a utilização de meios eletrônicos para a continuidade dos serviços judiciais, a legislação já validava a realização de audiências por videoconferência, como se observa, por exemplo, nos art. $185, \S 2^{\circ}$ do Código de Processo Penal, art. $334, \S 7^{\circ}$, e art. $236, \S 3^{\circ}$ do Código de Processo Civil, art. 22 da Lei no 9.099/95 e art. 46 da Lei no 13.140/2015. 
possam acessar os serviços judiciários diretamente da sua casa, do seu trabalho ou de outro lugar mais próximo a elas, eliminando a necessidade de visitas a fóruns e tribunais.

Nessa quadra e pelo escopo desse texto, é relevante tratar diretamente da relação das pessoas que vivem na pobreza com o Poder Judiciário24, quando tal relação depender de acesso às plataformas virtuais por meio de aparelhos eletrônicos conectados à internet, pois vislumbra-se que no futuro grande parte do serviço judiciário ou todo ele será mediado pela tecnologia (SUSSKIND, 2020).

Sucede que considerável parcela da população não tem acesso regular à internet devido aos custos, à falta de infraestrutura, ao analfabetismo, a deficiência física ou outras barreiras. Um em cada quatro brasileiros não pode acessar a internet25, apesar do direito previsto na Lei $\mathrm{n}^{\circ}$ 12.965/201426. Assim, implementar o uso da tecnologia para melhorar o funcionamento do sistema de justiça precisa ser associado à preocupação sobre os meios para alcançar a parcela dos excluídos digitais, ou seja, aqueles sem acesso ou cujo acesso é muito restrito às tecnologias digitais, em especial à internet, seja por falta de cobertura no local onde residem, seja por não saberem usar, ou por não poderem custear o serviço ou o equipamento eletrônico necessário para o acesso (computador, notebook, tablet, smartphone etc).

Entretanto, esta preocupação não deve ser superestimada e tomada como óbice intransponível para acesso à justiça, apesar de ser uma questão a ser resolvida.

Com efeito, antes do processo de tecnologização dos serviços judiciários, diversas outras barreiras já existiam para que as pessoas em situação de pobreza pudessem conhecer e reivindicar direitos. Isto é, antes de ser descortinada a dificuldade de acessar as plataformas digitais do Poder Judiciário, nas audiências presenciais e com os processos e comunicações em papel, tais pessoas já enfrentavam as barreiras da ignorância sobre o conteúdo dos seus direitos27, do desconhecimento das obrigações do Estado para com elas, das distâncias

24 Evidentemente, sem desprezar que o acesso à justiça não se resume ao acesso ao Poder Judiciário.

25 Nesse sentido, PNAD ( Contínua TIC) - Pesquisa Nacional por Amostra de Domicílios Contínua - Tecnologia da Informação e Comunicação. Um em cada quatro brasileiros não tem acesso à internet, 29 de abril de 2020, Ed. Estatísticas Sociais - IBGE. Disponível em: https://agenciabrasil.ebc.com.br/economia/noticia/2020-04/umem-cada-quatro-brasileiros-nao-tem-acesso-internet. Acesso em 10 jun. 2021.

26 Art. $4^{\circ}$ A disciplina do uso da internet no Brasil tem por objetivo a promoção: I - do direito de acesso à internet a todos; (...). Art. 24. Art. 24. Constituem diretrizes para a atuação da União, dos Estados, do Distrito Federal e dos Municípios no desenvolvimento da internet no Brasil: (...) X - prestação de serviços públicos de atendimento ao cidadão de forma integrada, eficiente, simplificada e por múltiplos canais de acesso, inclusive remotos..

27 A aptidão de uma pessoa para reconhecer os seus direitos e defendê-los adequadamente só passou a ser preocupação dos Estados com a transformação do conceito de direitos humanos, no momento em que os Estados 
geográficas da população da zona rural ou domiciliada em município que não é sede de comarca ou de seção judiciária, ou nas periferias urbanas.

Nesse sentido, a promoção da assistência digital para os excluídos digitais tem aptidão para, a um só tempo, superar a dificuldade de lidar com as inovações tecnológicas e abrir caminho para solucionar velhos problemas de acesso à justiça para as pessoas que vivem na pobreza. Afinal,

se o judiciário hoje é acessado por plataformas digitais, se esse acesso ao judiciário é parte dos direitos considerados fundamentais para a pessoa e, se entre os direitos de cidadania há o de navegar em ambiente digital, então promover inclusão digital para fins de acesso à justiça passa a não somente ser um objetivo, mas deve ser visto como uma necessidade para fins de adequação do discurso e da infraestrutura de sustentação do ordenamento jurídico. Em outros termos, sem inclusão digital não há como discutir ou promover acesso à justiça (SALDANHA; MEDEIROS, 2018, p. 7).

\section{REFLEXÕES SOBRE COMO ASSEGURAR OS MEIOS DIGITAIS PARA O ACESSO À JUSTIÇA DAS PESSOAS QUE VIVEM NA POBREZA}

$\mathrm{O}$ acesso à justiça desempenha um papel crucial na reivindicação de direitos, solução de litígios, combate à violência e outros problemas sociais e, por isso, é primordial pensar na construção de um cenário institucional que não discrimine qualquer indivíduo ou grupo, sobretudo os mais pobres, privados de adquirir ferramentas, capital social e conhecimentos básicos para se envolver com o sistema de justiça. Logo, na era digital as ferramentas devem ser implantadas visando à aproximação do sistema de justiça com a sociedade de forma universal.

Imagine-se que ao desenvolver uma cadeira que sirva a pessoas fisicamente debilitadas, o projeto de construção deve levar em conta o usuário, pois se, ao final, a tecnologia (cadeira) apresentar-se mais difícil de usar do que uma cadeira normal, então o projeto fracassou. De igual modo, a adoção da tecnologia digital pelo sistema de justiça, em especial pelo Poder Judiciário, precisa preocupar-se com o usuário, o destinatário final, para preencher lacunas e democratizar o acesso.

Logo, é de se esperar, de início, que o Estado cumpra o dever de assegurar aos brasileiros o amplo acesso à internet, conforme a Lei no 12.965/2014. Contudo, há casos em que simplesmente ter acesso a um dispositivo ou conexão com a internet é insuficiente.

liberais dos séculos XVIII e XIX deram lugar a sociedades com caráter mais coletivo. A partir de então, o acesso à justiça passou a ser visto como o mais básico dos direitos humanos (CAPPELLETTI; GARTH, 1988, p. 9-13). 
Assim, outras medidas podem ser implementadas tornando compatível a inovação tecnológica com o objetivo geral de proporcionar o acesso à justiça.

Com o intuito de propor uma solução ao problema, pode-se enquadrar em um grupo de aparentemente excluídos da internet ou também chamados de "usuários secundários" aqueles cidadãos carentes de capacidades (insuficiências sociais ou pessoais), tais como, as pessoas mais idosas, pessoas com deficiência, indígenas, comunidades rurais e remotas e pessoas com dificuldade no idioma, como os refugiados. Em paralelo, podem ser agrupadas como "usuários dificilmente acessíveis" as pessoas que, independentemente de apresentar quaisquer das características do outro grupo, sofrem de insuficiência de bens básicos (economicamente desfavorecidos com carência de necessidades básicas) (SUSSKIND, 2020).

\begin{abstract}
Com relação aos cidadãos com menos recursos ou 'dificilmente acessíveis', se encontram entre os mais vulneráveis da sociedade e com frequência se veem privados não só de apoio legal, mas também de serviços sanitários, sociais e, para ser sincero, da compaixão de muitos de seus semelhantes. A justiça distributiva clama para que estas pessoas recebam o apoio que lhes permita compreender e fazer cumprir seus direitos. Se nossos serviços judiciais têm que ajudar alguém, certamente deveria ser aqueles que não podem ajudar-se a si mesmos. (SUSSKIND, 2020, E-book, livre tradução).
\end{abstract}

Os "usuários secundários" acessam as plataformas digitais por interposta pessoa, ou seja, não são usuários por si mesmos, sendo outros que navegam nos ambientes digitais em seu nome. Já os "usuários dificilmente acessíveis" nem têm essa chance, não acessam nem por si nem por terceiros. A possível solução que alcance ambos os grupos pode passar por algum tipo de ajuda prática (SUSSKIND, 2020), seja para promover o treinamento e alfabetização digital, seja para que os "usuários dificilmente acessíveis" se tornem "usuários secundários".

Para isso, iniciativas fundadas na cooperação entre Poder Público e sociedade podem dar início à construção do cenário desejado. Por exemplo, o próprio Poder Judiciário28 pode capacitar agentes multiplicadores que alcancem as pessoas em situação de pobreza e as orientem ou alfabetizem digitalmente para uso das plataformas eletrônicas judiciais. Nesse propósito pode ser envolvida a Defensoria Pública29, responsável por promover a educação

28 De acordo com os arts. 198 e 199 do Código de Processo Civil as unidades do Poder Judiciário devem disponibilizar, de forma gratuita, equipamentos necessários para a prática de atose consulta de processos eletrônicos, bem como a acessibilidade às pessoas com deficiência.

29 "Noutras palavras, cabe aos defensores públicos aplicar no seu quotidiano profissional a sociologia das ausências, reconhecendo e afirmando os direitos dos cidadãos intimidados e impotentes, cuja procura por justiça e conhecimento do(s) direito(s) têm sido suprimidos e ativamente reproduzidos como não existentes. [...] É preciso que os cidadãos se capacitem juridicamente, porque o direito, apesar de ser um bem que está na sabedoria do povo, é manejado e apresentado pelas profissões jurídicas através do controle de uma linguagem 
em direitos e, de igual modo, prestar assistência jurídica (inclusive, digital). Outros atores podem ser incluídos na equação como a OAB, o Ministério Público e organizações não governamentais.

Ademais, não se pode esquecer da logística requerida, isto é, equipamentos com acesso à internet, que podem ser ofertados em pontos de acesso comunitário como associações de moradores, sindicatos, ou outros locais descentralizados por meio de parcerias com as prefeituras, para fornecimento dos aparelhos e disponibilização de material humano (servidor público ou voluntário treinado) para realizar a navegação digital em nome de outrem, como um serviço de atenção especial aos que necessitem. Postos avançados de atendimento do Poder Judiciário também podem ser adotados com o mesmo propósito, como ocorre, exemplificativamente, no Tribunal de Justiça da Paraíba e Tribunal de Justiça de Roraima, que noticiaram a instalação de postos de atendimento nos termos judiciários e em aldeias indígenas 30 .

Deveras, os dispositivos eletrônicos podem capacitar de maneira significativa os menos favorecidos e ao mesmo tempo servir de canal de comunicação e aproximação com o Poder Judiciário, como se vê do exitoso exemplo da BarefootLaw31, uma organização sem fins lucrativos que, em Uganda, capacita as pessoas com informações jurídicas gratuitas, por meio do uso inovador da tecnologia digital, para que possam usá-las no desenvolvimento de soluções jurídicas para suas necessidades de justiça (SUSSKIND, 2020).

Essas sugestões não são receitas prontas ou simplificações inúteis, servindo como ponto de partida, pois, na prática, as necessidades locais e globais podem ser atendidas de outras formas com a cooperação do Poder Público, de outras entidades e da sociedade civil organizada.

\section{CONSIDERAÇÕES FINAIS}

técnica ininteligível para o cidadão comum. Com a capacitação jurídica, o direito converte-se de um instrumento hegemônico de alienação das partes e despolitização dos conflitos a uma ferramenta contra-hegemônica apropriada de baixo para cima como estratégia de luta. A função da prática e do pensamento emancipador consiste em ampliar o espectro do possível através da experimentação e da reflexão acerca de alternativas que representem formas de sociedades mais justas" (SANTOS, 2011, p. 68-69).

30 Disponível em: https://www.tjpb.jus.br/noticia/justica-mais-proxima-do-cidadao-tjpb-disciplina-instalacaodos-postos-avancados-patj e https://www.tjrr.jus.br/index.php/noticias/15206-acesso-a-justica-waimiri-atroarirecebe-posto-avancado-de-atendimento-judiciario. Acesso em: 10 ago. 2021.

31 Sugere-se conferir as ações desenvolvidas em seu sítio eletrônico. Disponível em: https://barefootlaw.org/. Acesso em 20 jun. 2021. 
As dificuldades de acesso à justiça são múltiplas e demandam diversas abordagens de tratamento, em especial para as pessoas que vivem em situação de pobreza, em razão de insuficiências sociais ou pessoais que as impedem de reconhecer adequadamente os seus direitos e de buscar proteção quando há uma situação de violação ou ameaça a direito.

A despeito das conhecidas barreiras de acesso à justiça, tratadas a partir dos estudos de Mauro Cappelletti e Bryant Garth na década de 1970, hoje se apresenta uma nova questão a ser resolvida: o impacto da tecnologia no acesso à justiça e, notadamente, no acesso ao Poder Judiciário. Isso porque a utilização de aparelhos eletrônicos ligados à internet tem modificado os hábitos nos campos sociais e econômicos, e de igual maneira, mudado a forma como o Poder Judiciário oferta os seus serviços à sociedade.

Não há dúvida de que o desenvolvimento das funções do Poder Judiciário em plataformas eletrônicas tem potencial para otimizar os serviços e alcançar áreas isoladas e negligenciadas e, desse modo, permitir que as pessoas em situação de pobreza desfrutem de uma oportunidade real de atendimento em igualdade de condições com os demais cidadãos.

$\mathrm{Na}$ era digital as audiências ocorrem por videoconferência, as comunicações e atos processuais são eletrônicos, com perspectiva de que cada vez mais a atuação jurisdicional se dê em meio digital (ou eletrônico, ou virtual). Por isso, é necessário construir políticas, influenciar projetos e programas, com o objetivo de que essa realidade não exacerbe as dificuldades daqueles que vivem em situação de pobreza, considerados excluídos digitais.

É certo que o acesso universal à internet é um importante direito a ser efetivado, mas pode não ser suficiente, razão pela qual se sugere a adoção de medidas que promovam a inclusão digital, como instrumento de democratização do acesso à justiça. Por isso, ao longo do texto, apresentou-se um cenário otimista de como a assistência digital pode fazer com que o impacto da tecnologia seja positivo para o acesso à justiça, dependendo das iniciativas integradas e estratégicas do Poder Judiciário, dos demais atores do sistema de Justiça e da sociedade.

\section{REFERÊNCIAS}

BRASIL. Conselho Nacional de Justiça. Justiça em números 2020: ano-base 2019. Brasília: CNJ, 2020.

CAPPELLETTI, Mauro; BRYANT, Garth. Acesso à Justiça. Porto Alegre: Sérgio Antônio Fabris Editor, 1988. 
CRESPO, Antônio Pedro Albernaz; GUROVITZ, Elaine. A pobreza como um fenômeno multidimensional. RAE electron., São Paulo, v. 1, n. 2, p. 1-12, Dec. 2002. Disponível em http://www.scielo.br/scielo.php?script=sci_arttext\&pid=S1676-

$56482002000200003 \& \operatorname{lng}=$ en\&nrm=iso. Acesso em 05 jun. 2020.

CUEVA, Ricardo Villas Bôas. Inteligência artificial no judiciário. In:

NUNES; et al.. (org.). Inteligência artificial e direito processual: os impactos da virada tecnológica no direito processual. Salvador: Juspodivm, 2021, p. 79-91.

HOFFMANN-RIEM, Wolfgang. Teoria geral do direito digital: transformação digital: desafios para o direito. Rio de Janeiro: Forense, 2021, E-book (não paginado).

MARCACINI, Augusto Tavares Roda. Assistência jurídica, assistência judiciária e justiça Gratuita. São Paulo, Forense, 2009.

MORENO, Pablo Ernesto Medrano. El camino de "los pobres" hacia la Justicia Administrativa. In: PINZÓN, Miguel Malagon; VELÁSQUEZ, Carolina Moreno. Problemas Actuales del Derecho Administrativo. Bogotá: Unversidad de Los Andes, 2020.

SADEK, Maria Tereza; LIMA, Fernão Dias de ARAÚJO, José Renato de Campos. O judiciário e a prestação da justiça. In: SADEK (org.). Acesso à justiça. São Paulo: Fundação Konrad Adenauer Stiftung, Caderno de Pesquisas n. 23, 2001.

SALDANHA, Alexandre Henrique Tavares; MEDEIROS, Pablo Diego Veras. Processo judicial eletrônico e inclusão digital para acesso à justiça na sociedade da informação. Revista de processo. Vol. 277/22018, mar. 2018, p. 541-561.

SANDEFUR, Rebecca L. The importance of doing nothing: everyday problems and responses of inaction, 2007. Dispoível em: https://ssrn.com/abstract=1599755. Acesso em: 10 ago. 2021.

SANDEFUR, Rebecca L. What we know and need to know about the legal needs of the public. South Carolina Law Review, Vol. 67, 2016, p. 443-460. Disponível em:

https://ssrn.com/abstract=2949010. Acesso em: 10 ago. 2021.

SANTOS, Boaventura de Sousa. Para uma revolução democrática da justiça. 3 ed. São Paulo: Cortez, 2011.

SCHWAB, Klaus. A quarta revolução industrial. São Paulo: Edipro, 2016.

SEN, Amartya. Desenvolvimento como liberdade. São Paulo: Companhia das Letras, 2010.

SPENGLER, Fabiana Marion; PINHO, Humberto Dalla Bernardina de. A mediação digital de conflitos como política judiciária de acesso à justiça no Brasil. Revista da Faculdade de Direito UFMG. Belo Horizonte, n. 72, jan./jun. 2018, p. 219/257. 
SUSSKIND, Richard. Tribunales online y la justicia del futuro. Traducción de la obra original "Online courts and the future of justice". Wolters Kluwer: Madrid, 2020. E-book (não paginado).

WATANABE, Kazuo. Acesso à justiça e sociedade moderna. In: GRINOVER, Ada Pellegrini et. al. (coord.). Participação e processo. São Paulo: RT, 1988, p. 128-135.

WONG, Shing Yip, Understanding poverty: comparing basic needs approach and capability approach, 2012. Disponível em: http://dx.doi.org/10.2139/ssrn.2066179. Acesso em: 05 jun. 2020.

YOUNG, Iris Marion. Equality of whom? Social groups and judgments of injustice. The Journal of Political Philosophy. Vol. 9, n. 1, 2001, p. 1-18. 